\title{
QUESTÕES DE AUTENTICIDADE NA ERA DO PATRIMÔNIO ESPETACULAR
}

Priscila Henning ${ }^{1}$

\section{Resumo}

Atualmente, a questão da preservação de nosso legado arquitetônico, histórico e/ou artístico vem sendo amplamente discutida, não apenas no meio acadêmico, como pela sociedade em geral. Por todo o país surgem cada vez mais projetos de preservação cultural que unem tanto as iniciativas privadas quanto organismos públicos, muitas vezes aplaudidos pela mídia e apoiados pelos usuários. A princípio, este quadro é positivo e benéfico, pois estimula a conservação de nossos bens culturais e a retomada da própria identidade da sociedade a partir de sua trajetória ao longo do tempo. No entanto, a associação insistente da preservação do patrimônio com a indústria cultural do espetáculo, incluindo neste contexto a relação indissociável com o turismo espetacular e as distorções geradas pela indústria da informação, faz com que seja necessária a discussão de um conceito basilar que pauta a ação do preservador: a questão da autenticidade.

O conceito de autenticidade desperta algumas das questões essenciais que cercam a preservação do patrimônio cultural: o que se está preservando, de que forma, e por quê? Esta questão é crucial: a partir da noção de que o bem em si, ou as dinâmicas sociais e históricas que este encerra, são justificativas para a sua conservação, torna-se necessário investigar as razões para sua distorção, desfiguração ou modificação deliberada. Para fins deste trabalho, a noção do espetáculo é ressaltada por ser uma relação contraditória, aparentemente positiva, porém que atinge diretamente a própria essência do patrimônio cultural. Ao mesmo tempo, é um espelho da sociedade contemporânea, de seus valores e mecanismos, e de sua relação com a cultura, gerando uma complexa dinâmica de significados e relações que influenciam diretamente a ação e compreensão da preservação do patrimônio cultural.

Palavras-chave: Autenticidade, patrimônio cultural, turismo espetacular.

\begin{abstract}
Recently, the problem of preserving our architectural, historic and artistic legacy has been widely discussed, not only in the academic world, but in society in general as well. All over the country more and more projects of cultural preservation have appeared, uniting both private enterprises and governmental institutions, usually applauded by the media and approved by the users. At first, this scenario is positive and advantageous, as it stimulates the conservation of our cultural heritage and the retrieval of society's own identity, considering its development in time. However, the insistent association of heritage conservation with the cultural industry of the spectacle, including in this context the firm relation with spectacular tourism and the distortions generated by the industry of information, makes it necessary to discuss a basic concept that should guide the action of the preserver: the idea of authenticity.

The concept of authenticity incites some essential questions that surround the conservation of cultural heritage: what is being preserved, in which manner and why? This is a crucial question: parting from the notion that the building or object in itself, or the social and historic dynamics it encompasses, are reason enough to justify its conservation; it

\footnotetext{
1 Programa de Mestrado da Faculdade de Arquitetura e Urbanismo da Universidade de São Paulo (FAU USP), com auxílio da FAPESP. Orientadora: Beatriz Mugayar Kühl.
} 
becomes necessary to investigate the reasons for the occurrence of distortion, disfiguration and deliberate modification. For this work, the notion of spectacle is emphasized because of its contradictory and apparently beneficial nature - however it affects the very essence of cultural heritage. It remains the mirror of contemporary society, its values and mechanisms, and its understanding of culture, generating a complex dynamics of significations and relations that influence directly the action and comprehension of cultural heritage preservation.

Keywords: Authenticity, cultural heritage, spectacular tourism.

Atualmente, a questão da preservação do patrimônio cultural está sendo gradativamente mais aceita e compreendida pela sociedade em geral. Pode-se dizer que a própria conscientização da necessidade da preservação tornou-se mais profunda a partir do século XX, mais especificamente após as duas Guerras Mundiais - em termos do patrimônio histórico e arquitetônico, devido à destruição dos edifícios históricos e monumentos durante este período. No entanto, a necessidade de se preservar o legado de nossos antepassados para as gerações posteriores já havia sido percebida há muito tempo, até em civilizações muito antigas. Por exemplo, o relato do viajante Pausânias, durante sua visita a Olympia no primeiro século d.C, onde ele cita a seguinte mensagem que ele viu numa placa de bronze fixada a um pilar:

Stranger, I am a remnant of a famous house.

I, who once was a pillar in the house of Oenomaüs;

Now by Cronus' son I lie with these bands upon me,

A precious thing and the baleful flame of fire consumed me not.

(PAUSANIAS, citado por JOKILEHTO, 1985, p.5).

Apesar de este trecho demonstrar a consciência de que o fragmento "remanescente de uma casa famosa" era algo "precioso" - portanto, requer cuidado -, a noção de preservação do patrimônio enquanto uma prática que necessitava de uma metodologia própria só surgiu, de forma organizada, no século XVIII. Antes disto, por mais que houvesse a intenção de conservar os monumentos (palavra que provém do verbo monere em latim, que significa advertir, lembrar, já demonstrando que, para os romanos, o monumento era algo que transmitia uma memória ou um alerta do passado [CHOAY, 2001, p. 28]), a prática de restaurar ou conservar era feita sem muito questionamento ou diretrizes, seguindo o gosto da época ou a intenção "artística" do próprio restaurador, que muitas vezes dependia apenas da imaginação para deduzir o estado original da obra. Embora os questionamentos e críticas a isto já surgissem, na voz de Bellori ou Winckelman, dentre outros, foi apenas com o surgimento da idéia da Nação iluminista que as atenções se voltaram para "os monumentos nacionais como evidências materiais da história da nação" (JOKILEHTO, 1985, p.6), sendo então instituídos os primeiros organismos oficiais de proteção ao patrimônio cultural. Por exemplo, na França pós-revolução, foi nomeado o primeiro Inspetor dos Monumentos Históricos da França, Ludovic Vitet, em 1830, e a primeira Comissão dos Monumentos Históricos, em 1837 (CHOAY, op.cit., p.12).

Desde o início de sua formalização, a preservação do patrimônio tornou-se um cabo de guerra entre duas formas contraditórias de pensar: de um lado, os adeptos da conservação pura e simples do objeto, e, do outro, os que defendem intervenções modernas que buscam reconstruir partes faltantes, repristinar a aparência estética (a chamada "hipermanutenção") ou que defendem o "retorno" a uma dada configuração formal, de algum ponto de sua história. A dificuldade deste entendimento se dá devido à 
própria essência complexa da construção histórica. A princípio, é um bem de uso, e sua funcionalidade não deve ser deixada de lado. No entanto, um edifício histórico, como bem descreveu Anatole France, é como um livro "onde as contribuições de diferentes gerações formam os capítulos" (in JOKILEHTO, 1985, p.7). Ou seja, impressa em suas formas, na pátina do tempo, nas ruínas, ou nas adições e reformas ao longo do tempo, está seu caráter de documento histórico. Por fim, por ser arquitetura, é uma obra de arte. Não se deve deixar de lado também sua instância estética, que muitas vezes é sua maior contribuição cultural e seu primeiro valor. Esta dupla instância histórica e estética foi muito bem analisada por Cesare Brandi, idealizador do restauro crítico, que ainda hoje é a referência maior para guiar a ação do restaurador (BRANDI, 2001) e cujas teorias e abordagem proposta foram base para a elaboração da Carta de Veneza, de 1964, que ainda é o documento oficial referencial em preservação.

Atualmente, estas questões se tornam mais acaloradas com o acréscimo de um novo fator: a consolidação da indústria do turismo. O turismo, já há muito tempo, contribuiu para o alastramento das idéias preservacionistas. Jokilehto cita, por exemplo, o fato de que em Roma, "durante o Iluminismo no século 18, (...) muitos visitantes expressaram preocupação com a má condição de seus monumentos antigos e os afrescos de Rafael, que eram considerados de valor tão universal que sua conservação não era problema apenas dos romanos, mas elevou-se acima de todas as fronteiras entre países e religiões" (JOKILEHTO, 1985, p.6). Além de despertar o interesse de sítios históricos, a renda gerada pelo turismo muitas vezes é revertida para a própria manutenção e conservação dos monumentos, contribuindo para que construções antes abandonadas passassem a ser valorizadas e mesmo responsáveis pelo desenvolvimento de uma região como um todo (JOKILEHTO, 1998, p.18). A idéia de que "o turismo [é] um meio de preservação dos monumentos" esteve presente em vários documentos oficiais ${ }^{2}$. No entanto, a indústria do turismo cultural trouxe consigo inúmeros efeitos negativos - sendo o principal deles a destruição eventual do próprio objeto que justifica o turismo (CHOAY, 2001, p. 15). A Carta do Turismo Cultural, de 1976, declara que "qualquer que seja sua motivação e os benefícios que possui, o turismo cultural não pode estar desligado dos efeitos negativos, nocivos e destrutivos que acarreta o uso massivo e descontrolado dos monumentos e sítios", sugerindo então que se haja um movimento em prol da educação patrimonial, tanto dos usuários visitantes quanto dos organizadores e planejadores destas visitas.

No entanto, um conflito atual se dá devido à espetacularização do patrimônio, que muitas vezes atende aos interesses econômicos do turismo cultural. Há a necessidade de se chamar atenção para a abordagem que se faz do patrimônio quando estes interesses estão envolvidos. Segundo Carlos Lemos, muitas vezes:

Preserva-se em atendimento às exigências do turismo, a grande indústria moderna, que maneja quantias incríveis enquanto vai forjando nos sítios visitados imagens, às vezes ressuscitadas, definidoras de peculiaridades culturais regionais aptas a estar sempre despertando a curiosidade dos viajantes ávidos de novidades. O turismo nasceu em volta de bens culturais paisagísticos e arquitetônicos

\footnotetext{
2 A citação foi extraída da Resolução de São Domingos, de dezembro de 1974, em evento oficial da Organização dos Estados Americanos (OEA), sendo os signatários deste documento os países filiados a esta organização - o Brasil entre eles. Outro momento, talvez mais específico, onde os efeitos positivos e negativos do turismo cultural são discutidos, é na Carta do Turismo Cultural, de Bruxelas, em 1976, promovida pelo ICOMOS (Comitê Internacional de Monumentos e Sítios).
} 
preservados, e hoje, cada vez mais, vai exigindo a criação de mais cenários, de mais exotismos, provocando quadros artificiais, inclusive (LEMOS, 2000, p. 30).

A questão que se levanta, então, é paradoxal: o que justifica o turismo cultural não é o valor estético e/ou histórico do objeto? Mas se este objeto é distorcido ou desfigurado ao ser "embalado para consumo", contribuindo para a perda de seus atributos, o próprio turismo cultural não se justifica mais.

Este paradoxo diz respeito, principalmente, a um conflito metodológico e epistemológico, que cerca a definição do conceito de autenticidade.

A autenticidade é base da doutrina moderna da conservação e da restauração dos monumentos históricos, sendo palavra-chave dos documentos (convenções e cartas internacionais) relativos à salvaguarda do patrimônio cultural ${ }^{3}$, mas não se encontra em nenhum deles uma definição precisa do conteúdo e sentido que é conveniente dar a ela inclusive porque o conceito, bastante complexo, apresenta diferenças consideráveis segundo as culturas e grupos sociais.

Jokilehto considera que a Carta de Veneza, de 1964, tinha como "mensagem principal (...) o desenvolvimento de uma abordagem crítica da restauração conservativa de propriedades históricas. Uma distinção rigorosa foi feita entre o que era historicamente verdadeiro e genuíno, e o que era uma adição moderna ou réplica; daí o apelo por autenticidade" (JOKILEHTO, 1998, p. 17). Esta concepção de autenticidade provém, entre outras fontes, da noção de Walter Benjamin sobre autenticidade. Para Benjamin, a autenticidade reside na unicidade da obra, na sua materialidade única, no seu "aqui e agora". A autenticidade não compreende apenas o objeto em si, mas também "a quintessência de tudo que foi transmitido pela tradição, a partir de sua origem, desde sua duração material até seu testemunho histórico" (BENJAMIN, 1994, p. 168). Estas características inerentes ao objeto, impalpáveis e simbólicas (pois diz respeito a uma tradição) e, portanto, irreprodutíveis, compõem o conceito de "aura".

Ou seja, entende-se que "o autêntico é identificado com o original, e o inautêntico com a cópia ou reprodução" (GONÇALVES, 1988, p. 265). A cópia, réplica ou reprodução, na concepção de Benjamin, seriam desprovidas da "autoridade da coisa, do seu peso tradicional". Pois,

mesmo na reprodução mais perfeita, um elemento está ausente: o aqui e agora da obra de arte, sua existência única, no lugar em que ela se encontra (...) Essa história compreende não apenas as transformações que ela sofreu, com a passagem do tempo, em sua estrutura física, como as relações de propriedade em que ela ingressou (...) são o objeto de uma tradição, cuja reconstituição precisa partir do lugar em que se achava o original (BENJAMIN, op. cit., p. 167-168).

Raymond Lemaire afirma que, especificamente no caso das artes plásticas, que se situam no espaço (em oposição às artes como a literatura e a música, que, segundo Henri Focillon, se situam no tempo), a autenticidade requer a presença do suporte original da mensagem. Em seminário proferido na Conferência de Nara sobre Autenticidade ${ }^{4}$, em 1994, Lemaire definiu autenticidade semiologicamente:

...[É] essencialmente uma relação de verdade e sinceridade entre o emissor de uma mensagem e o conteúdo desta. É 'autêntica' uma mensagem que é transmitida sem

\footnotetext{
${ }^{3}$ O conceito surge oficialmente, pela primeira vez, na Carta de Veneza, de 1964, também do ICOMOS. Esta carta é ainda hoje referência para a salvaguarda do patrimônio mundial.

4 "Nara Conference on Authenticity in Relation to the World Heritage Convention", realizada em Nara, no Japão, em novembro de 1994. Esta conferência gerou o "Documento de Nara" que dispõe sobre a autenticidade na conservação do patrimônio mundial.
} 
sofrer alteração, mesmo em suas nuanças, de um 'emissor' a um 'receptor' (...) É evidente que a transmissão tem mais chance de ser correta quando (...) o emissor não tenha sofrido, em relação à mensagem da qual é suporte, nenhuma alteração que possa modificar ou alterar o conteúdo exato dessa mensagem (LEMAIRE, 1994, p.1).

Assim, a obra de arte (e podemos incluir neste caso as obras de arquitetura), para transmitir sua mensagem, recorre às formas que se configuram no espaço. "No âmago da obra, seu papel essencial e imutável é o de obra de arte e de transmitir (...) a natureza e o conteúdo da mensagem (...) É nesse sentido que essas formas são qualificadas de únicas" (LEMAIRE, op.cit., p. 2). No entanto, Lemaire também discute o peso da tradição da obra, da sua existência ao longo do tempo: "A alteração ou a modificação da mensagem é (...) quase inevitável; raras são as obras de arte de uma certa idade que disso escaparam. O tempo ou o homem apagam formas iniciais, sobrepõem ou inserem inovações na composição primitiva e, por conseqüência, interferem na natureza ou no sentido da obra inicial" (LEMAIRE, op. cit., p. 3). Segundo Lemaire, estas alterações são "autênticos testemunhos da história da obra" mas possuem, todas elas, um valor de autenticidade, ligadas à materialidade da obra. Assim, Lemaire retoma a dualidade de Brandi: por um lado, a autenticidade ligada ao valor enquanto obra de arte; por outro, o valor de documento histórico. Estabelecer uma hierarquia entre estes valores se torna, então, a grande dificuldade. Neste ponto, Lemaire declara: "De tanto ver no monumento apenas um 'documento de pedra', chegou-se a considerar que esta é sua função essencial. Esquece-se que a razão fundamental e geralmente única de sua criação, e portanto seu papel primeiro, é ‘servir' e ser uma 'obra de arte"' (LEMAIRE, op. cit., p. 8).

A dificuldade de se estabelecer um critério definido de autenticidade, pelo menos para fins práticos, requer uma reflexão epistemológica do termo. Com esta intenção, Françoise Choay, também em participação na Conferência de Nara, procurou traçar a evolução do termo. A princípio utilizada para conferir autoridade em textos normativos tanto em Direito como na Religião, o conceito se expandiu à época do Renascimento, porém sua utilidade prática se restringiu à sua antítese: distinguir os falsos. No século XIX, quando a disciplina teórica e prática do restauro passou a se organizar, a noção de autenticidade foi transposta, sem a necessária precaução, de campos mais exatos como a arqueologia para o campo do restauro, a despeito de três condições negativas atreladas ao conceito de autenticidade:

A primeira é que a autenticidade não provém de uma apreciação subjetiva, mas emana de uma autoridade institucional, o direito, a religião ou a razão científica. A segunda é que não se pode aplicar a noção de autenticidade a um significado como o faz uma derivação surgida mais recentemente. Desde mais de meio século todo o trabalho lingüístico, semântico e a psicolingüística, confirma a intuição dos filósofos e dos poetas: o sentido não pode ser fixado ou congelado. Ele existe somente após uma apropriação ativa que é a cada vez uma recriação (...) A terceira condição, finalmente, liga-se ao fato de não se poder fixar o estado de um objeto que, diferentemente do texto e por sua materialidade, não cessa de se alterar a partir do momento em que começa a ser modificado pelo tempo (CHOAY, 1994, p. 3).

Com todas estas limitações, a aplicação do termo autenticidade como uma defesa fetichista de um original "fictício", se torna "relativista" e permite deturpações de todo tipo, inclusive por seu caráter vago. Aplicado desta maneira, Choay acredita que o termo não é operacional para a disciplina de patrimônio histórico. 
Outra questão que Choay levanta é relativa à noção de "patrimônio mundial". A idéia de autenticidade, justamente por seu caráter simbólico (a "aura" descrita por Benjamin), possui diferenças significativas em outras culturas. Enquanto no Ocidente, principalmente na tradição européia, perdura a relação fetichista com a idéia do "original" único, no Japão a relação dos usuários com os templos tradicionais traz outra concepção de autenticidade. Os templos xintó são exemplos de uma tradição que preserva através da destruição sistemática: os templos são desmantelados periodicamente e depois novamente reconstruídos de forma idêntica, assim preservando sua integridade. Enquanto que no Ocidente tal prática se mostra inconcebível em termos de conservação, deve-se levar em conta que, no Japão, a relação tradicional com o monumento continua a mesma. "O templo de Ise é um monumento, bem vivo: na visão de mundo Xintó sua destruição periódica é necessária ao seu funcionamento; ela é exigida como um ato de purificação não somente do local sobre o qual foi edificado, mas da matéria corruptível (a madeira) de sua estrutura" (CHOAY, op.cit., pp. 8-9). Neste caso, se formos levar em consideração a "aura" de Benjamin, veremos que o peso da tradição milenar está presente apesar da inexistência da materialidade original - trata-se de uma visão diversa da Ocidental.

No entanto, é o caso americano o mais interessante na atualidade. Por todos os Estados Unidos (e, devido a sua influência cultural, também no restante do mundo) surge um novo modelo de "preservação": as réplicas. As reconstruções não são novidade, tendo ocorrido ao longo de toda a história humana. No entanto, mesmo em face de toda a discussão atual acerca da autenticidade em patrimônio histórico, surge a construção de cenários espetaculares que procuram reproduzir em pormenores não apenas as construções que supostamente existiam antes - mas inclusive um modo de vida distante, com seus costumes, hábitos, vestimentas, etc. O patrimônio passa a ser um simulacro de tempos passados, como se o tempo, naquele lugar, tivesse parado. Não se trata de conservar algo que permaneceu, mas de reconstruí-lo identicamente, com fidelidade em documentos e fotografias. É a simulação de uma realidade que não mais existe, nem no tempo, nem no espaço - e que talvez jamais tenha existido desta forma.

O conceito de espetáculo, segundo Guy Débord, "é a afirmação da aparência e a afirmação de toda vida humana - isto é, social - como simples aparência" (DÉBORD, 1997, p.16). Ou seja, é a imagem destacada do objeto real, que se sobrepõe ao objeto - e as relações entre as pessoas se dão através destas imagens. "O obstáculo apresenta-se ao mesmo tempo como a própria sociedade, como uma parte da sociedade e como instrumento de unificação. Como parte da sociedade, ele é expressamente o setor que concentra todo olhar e toda consciência. Pelo fato deste setor estar separado, ele é o lugar do olhar iludido e da falsa consciência" (DÉBORD, op.cit., p.14). Este cenário da separação consumada é fruto, segundo Débord, do modo de produção atual. Em termos do patrimônio histórico, a própria história virou artigo de consumo. Os cenários impecáveis, ascéticos exibem a paródia da história, devidamente explicados, exibidos, e palatáveis para o consumo ${ }^{5}$. Considerando que o simulacro é "cópia idêntica de um original que nunca existiu" (PLATÃO apud JAMESON, 1997, p. 45), pode-se afirmar que a encenação dos simulacros

\footnotetext{
${ }^{5}$ É exemplo desta forma de espetacularização do patrimônio a cidade de Colonial Williamsburg, nos Estados Unidos, inteiramente recriada a partir de poucos remanescentes autênticos do ano de 1775. Uma análise desta encenação pode ser encontrada no artigo de José R. Gonçalves citado, e também através de site na internet: The Official Web Site of Colonial Williamsburg: the world's largest living history museum. |online $\mid$. Disponível em: http://www.history.org. Acesso em 24 de outubro de 2005.
} 
se tornou economicamente mais viável turisticamente que a realidade das construções simplesmente conservadas ao longo do tempo, usufruídas através do dia-a-dia de muitas gerações, muitas vezes sequer percebida no tecido urbano sem que haja uma indicação de que ali se trata de um monumento histórico autêntico. Segundo Jameson, "a cultura do simulacro entrou em circulação em uma sociedade em que o valor de troca se generalizou a tal ponto que mesmo a lembrança do valor de uso se apagou, uma sociedade em que, segundo observou Guy Débord, em uma frase memorável, 'a imagem se tornou a forma final da reificação" (JAMESON, op.cit., p. 45). A reificação desta imagem justifica as alterações e distorções feitas no objeto real, pois o simulacro, segundo Baudrillard, sucessivamente reflete uma realidade profunda, "mascara e deforma uma realidade profunda", e, por fim, "não tem relação com qualquer realidade: ela é o seu próprio simulacro puro" (BAUDRILLARD, 1991, p.13).

José Reginaldo Gonçalves nos conta que a categoria chamada de bistoric preservation, nos Estados Unidos, "designa aquele conjunto de atividades associadas à preservação, restauração e recriação de objetos, prédios, conjuntos arquitetônicos, cidades antigas (...) A categoria recriação (...) pode se estender e incluir também a reencenação dramática de eventos históricos ou mesmo do dia-a-dia de determinados períodos históricos" (GONÇALVES, 1988, p. 269). Para proceder atendendo à intenção de ser mais objetiva e precisa possível, a recriação é feita por equipes de profissionais multidisciplinares e com base em um extenso volume de documentos históricos, procurando manter ao máximo a veracidade técnica e estilística dos objetos antigos reais. Segundo Gonçalves, muitos destes locais são intensa e cuidadosamente estudados por arquitetos, historiadores e arqueólogos, procurando construir uma réplica exata.

Gonçalves sugere que, neste caso, poderia se tratar de uma "autenticidade nãoaurática", em referência ao conceito de Benjamin. "Parafraseando Benjamin, eu diria que elas constituem um exemplo de patrimônio cultural 'na época de sua reprodutibilidade técnica'. Elas tornam explícito o caráter artificial, construído e tecnicamente reproduzido, dos chamados patrimônios culturais" (GONÇALVES, 1988, p. 273) Os defensores americanos destes projetos costumam argumentar que, apesar de réplicas, as recriações não deixam de preservar um savoir-faire e perpetuar uma forma estética que não existe mais, contribuindo, de certa forma, para que as gerações futuras conheçam seu passado - que é a própria essência da preservação do patrimônio. No entanto, Jokilehto é categórico: citando o caso de uma cidade na Noruega, ele afirma que "as reconstruções não se qualificam como parte do tecido urbano (...) A área está listada como Patrimônio Mundial, mas a parte ocidental que foi reconstruída como réplica depois do incêndio de 1955 não foi incluída" (JOKILEHTO, 1985, pp. 9-10). Mesmo casos de restaurações excessivas num sítio antigo são criticados: "Fazer isto por motivos didáticos também pode ser questionado. Modelos didáticos podem ser úteis em museus para explicar formas anteriores de uma estrutura, mas restaurações excessivas no sítio original podem, ao contrário, resultar em confundir o que é original com o que é novo; podem, de fato, causar perda de fé no autêntico" (JOKILEHTO, 1985, p. 8).

Cada vez mais, esta forma de compreender o patrimônio histórico vem se difundindo. Mesmo no Brasil, já temos exemplos de espetáculos que são divulgados pela mídia como "patrimônio histórico preservado" quando são, em realidade, objetos distorcidos ou desfigurados, e mesmo reconstruídos (tanto física quanto simbolicamente). É necessário que haja uma reflexão profunda sobre este tema, sob risco de perdermos grande parte de nosso legado histórico em desfigurações imagéticas, processadas em seus 
"15 minutos de fama" midiáticos. Como bem explica Baudrillard, "a informação devora os seus próprios conteúdos (...) Em vez de fazer comunicar, esgota-se na encenação da comunicação. Em vez de produzir sentido, esgota-se na encenação do sentido. Gigantesco processo de simulação que é bem nosso conhecido" (BAUDRILLARD, 1991, p. 105).

O que se pode concluir com esta polêmica é que o problema da autenticidade é extremamente complexo: assim como outros conceitos em inúmeras áreas do conhecimento na atualidade, encontra-se num paradoxo, onde suas múltiplas interpretações geram definições até mesmo contraditórias. Podemos incluir sob o cunho de "patrimônio histórico autêntico" tanto uma construção milenar conservada, quanto uma réplica exata de uma cidade? Mesmo em suas definições restritas ao objeto real (e não ao simulacro ou ao objeto espetacularizado), o conceito já encontra conflitos em suas variadas instâncias estéticas, históricas e simbólicas, e teve seu sentido compreendido de formas distintas tanto ao longo da História, como por culturas diversas. Por este motivo, o conceito de "autenticidade", tão caro à preservação do patrimônio, deve ser simplesmente abandonado em face de suas contradições?

Ainda se compreende que o patrimônio histórico, dentro das definições trazidas pela UNESCO, ICOMOS e outras entidades internacionais, deve ser mantido autêntico no sentido benjaminiano do termo. Há toda uma trajetória de discussões, teorias e elaboração de uma metodologia específica para esta área de conhecimento, que não pode ser simplesmente trocada pelo culto ao lucro de uma indústria cultural do turismo. A teoria de Cesare Brandi, exposta em sua Teoria da Restauração, propõe soluções ponderadas desta problemática, através de uma ação crítica por parte do restaurador. Esta teoria continua atual, embora não solucione definitivamente este problema epistemológico. No entanto, estes conflitos devem ser discutidos profundamente, e a prática deve ser orientada por uma reflexão crítica sobre "o que, de que forma e para quê" se está preservando, sob o risco de perdermos o pouco que sobrou.

\section{Bibliografia:}

BAUDRILLARD, Jean. Simulacros e Simulação. Lisboa: Relógio d’Água Editores, 1991.

BENJAMIN, Walter. Magia e Técnica, Arte e Política: ensaios sobre literatura e história da cultura. São Paulo: Brasiliense, 1994.

BRANDI, Cesare. Teoria da Restauração. São Paulo: Ateliê, 2004.

CHOAY, Françoise. A Alegoria do Patrimônio. São Paulo: Estação Liberdade / Ed. Unesp, 2001.

Sept Propositions sur le Concept d'Autenticité et son Usage dans lês Pratiques du Patrimoine Historique. In: Nara Conference on Authenticity. Paris,

UNESCO, 1995. pp. 101-120. Tradução: Beatriz Mugayar Kühl.

DÉBORD, Guy. A Sociedade do Espetáculo. Rio de Janeiro: Editora Contraponto, 1997.

GONÇALVES, José Reginaldo. Autenticidade, Memória e Ideologias Nacionais: o problema dos patrimônios culturais. In: Revista Estudos Históricos, Rio de Janeiro, vol. 1, n. 2, 1988, pp. 264-275.

JAMESON, Fredric. Pós-Modernismo: a lógica cultural do capitalismo tardio. São Paulo: Ática, 1997. 
JOKILEHTO, Jukka. Authenticity in Restoration Principles and Practices. In: Bulletin of the Association for Preservation Technology (APT Bulletin), Vol. 17, No. 3/4, Principles in Practice. (1985), pp. 5-11. Tradução das citações: Priscila Henning.

International Trends in Historic Preservation: From Ancient Monuments to Living Cultures. In: Bulletin of the Association for Preservation Technology (APT Bulletin), Vol. 29, No. 3/4, Thirtieth-Anniversary Issue (1998), pp. 17-19. Tradução das citações: Priscila Henning.

LEMAIRE, Raymond. Autenticidade e Patrimônio Monumental. In: Restauro, Nápoles, 1994, n. 129, pp. 7-24. Tradução: Beatriz Mugayar Kühl.

LEMOS, Carlos. O que é Patrimônio Histórico. São Paulo: Ed. Brasiliense, 2000.

CARTAS PATRIMONIAIS: Os documentos e cartas internacionais citadas no texto estão todas disponíveis em: http://portal.iphan.gov.br/, sob o link "Cartas Patrimoniais". Acesso em 27 março 2006. 